\title{
Critical Care Concepts in IRAN During the Last Decades
}

\author{
Mehran Kouchek ${ }^{1, *}$ \\ ${ }^{1}$ Anesthesiology Research Center, Anesthesia and Critical Care Department, Imam Hossein Hospital, Shahid Beheshti University of Medical Sciences, Tehran, IR Iran \\ "Corresponding author: Mehran Kouchek, Anesthesiology Research Center, Anesthesia and Critical Care Department, Imam Hossein Hospital, Shahid Beheshti University of \\ Medical Sciences, Tehran, IR Iran. E-mail: mehrankouchek@yahoo.com
}

Received 2015 September 30; Revised 2015 October 15; Accepted 2015 October 30.

Over the past 30 years, the concepts of critical care medicine, simultaneously with international changes (1), in Iran changed not only regarding its practical and professional points but also by paying enormous attention to topics such as a national immediacy via responsible doctors, nurses, directors, policy makers and most important partly the People.

Of course, before these three decades, critical care concepts were partially understood, but it was the eight-year war between Iran and Iraq (1980 - 1988) that revealed the absolute necessities of a separated, well organized ward, which pays attention to Critically ill (war-injured) patients.

During that time, intensive care units (ICUs) in Iran were usually managed as open ICUs and we were far from the idea of running 'semi closed ' or even 'closed' ICUs for the country.

It was in the first decade that doctors and nurses worked hard together in order to decrease morbidity and mortality of war-injured victims, especially chemically exposed cases, and a tremendous need was felt to establish more organized or at least semi closed ICUs.

During the second decade, we reached a point when a specific training program for Anesthesiologists and Internists only for critical care medicine became necessary, and with the help of several groups from three major medical universities of the capital city (Tehran), a curriculum for fellowship of critical care medicine was developed very soon and was suggested to the Minister of Health at the time.

Now in the third decade, it is a great honor and pleasure that the country has its first group of Subspecialists (not just fellowships) of intensive care unit, the Iranian society of critical care with almost 100 members, the national board examination of critical care medicine and finalized ICU nursing Curriculum for training of several special nurses for ICUs being actively involved in Critical Care settings in the whole country (2).

During these hard times, we knew that we needed a site or journal to publish our professional work and at last our ICU Fellows at Shahid Beheshti University of Med- ical Sciences and the Iranian Society of Critical Care, admirably did this job, which was an outstanding quarterly journal; Archives of Critical Care Medicine with the cooperation of national and international researchers and scientists in the field of critical care medicine, critical care nursing, neuro critical care and so forth in the English language.

As the ministry of health in Iran recently decided to increase the number of ICU beds to 5000 for the whole country, we hope that very soon in the future we witness $20 \%$ $25 \%$ of all hospital beds as critical care beds in our health system.

Last but not least is the propagation of teaching and training programs outside of the capital city (Tehran), in other cities like Shiraz, Isfahan, Tabriz, Mashad and Ahvaz.

\section{References}

1. Juneja D, Nasa P, Singh O. Physician staffing pattern in intensive care units: Have we cracked the code?. World J Crit Care Med. 2012;1(1):10-4. doi: 10.5492/wjccm.v1.11.10. [PubMed: 24701396].

2. Vahedian-Azimi A, Ebadi A, Saadat S, Negarandeh R, Ahmadi F. Professors' view on the appropriate postgraduate degree in nursing education: A comparative study in two different sociocultural societies and literature review. Int J Med Rev. 2014;1(1):13-23. 